\title{
Evaluation and Comparison of Formocresol and Sodium Hypochlorite as Pulpotomy Medicaments in Treatment of Mandibular Primary Molars - A Randomized Controlled Study
}

\author{
Nadia Irshad Wani ${ }^{1}$, Navneet Kour ${ }^{2}$, Manju Verma ${ }^{1}$, Ishani Sharma ${ }^{3}$, \\ Pooja Chauhan ${ }^{3}$
}

\author{
${ }^{1}$ MDS Paediatric and Preventive Dentistry, ${ }^{2}$ MDS Periodontology and Implantology, \\ ${ }^{3}$ Senior Lecturer, Paediatric and Preventive Dentistry, BRS Dental College and Hospital, Sultanpur, Panchkula
}

Corresponding Author: Navneet Kour

\begin{abstract}
Background: the main idea behind the pulpotomy of a primary tooth is to remove the infected or inflamed coronal pulp tissues and cover the pulp with a suitable medicament or dressing which promotes healing and preserve the vitality of the teeth especially in young permanent teeth. A medicament should be biologically compatible, have healing capabilities, should be non cytotoxic, or mutagenic and with no carcinogenic potential.
\end{abstract}

Aim: the main aim of the study was to compare and evaluate the efficacy of commonly used two medicaments i.e. formocresol and sodium hypochlorite in pulpotomy of mandibular primary teeth.

Material and methodology: a randomized controlled single blinded clinical trial was done on 50 subjects of age ranging from 3 to 6 years with bilateral mandibular first or second molar requiring pulpotomy. The subjects were randomly divided into two groups with 25 subjects in each. Group I, consisted of subjects on which formocresol medicament was used after extirpation of coronal pulp while in Group II, 3\% sodium hypochlorite was used. Clinical along with the radiographic signs and symptoms were blindly recorded at an interval of $1,3,6$ and 12 months respectively.

Results: Statistically significant results were obtained in group II, when patients treated with $3 \%$ sodium hypochlorite. There was no major difference between the two medicaments used, but to the various adverse effects of formocresol, its usage has been limited.

Conclusion: within the limitation of the study, it was concluded that sodium hypochlorite medicament proved to have better prognosis and can be suggested as a pulpotomy agent for primary teeth. Although formocresol was found to have similar significant results can also be used as a medicament.

Keywords: Formocresol, Pulpotomy, Primary

Teeth, Sodium Hypochlorite

\section{INTRODUCTION}

Vital pulpotomy is the clinical treatment of choice for extensive caries with exposed pulp in primary molars. Pulpotomy can be defined as the procedure where surgical removal or amputation of the coronal pulp of the vital tooth is done to remove contaminated or diseased pulp. It is usually followed by the placement of a specific medicament over the intact pulp stump to stimulate the repair, mummify, and fix the remaining radicular pulp. ${ }^{1}$ The success of pulpotomy usually depends upon the correct diagnosis of the status of the pulp, control of bleeding after coronal pulp amputation, choice of material used in the base, restoration and microleakage. ${ }^{2}$ Control of pulpal hemorrhage is an indispensible step in pulpotomy procedure. Many studies conducted have indicated that if hemorrhage 
not controlled the blood clot forms on the pulp surface which prevents intimate contact between the capping material and pulpal tissue which results in a chronic inflammatory response. ${ }^{3}$ Pulpotomy therapy is usually classified according to the treatment objectives which include preservation (minimal devitalization and non-induction), devitalization (cauterization and mummification) or regeneration (reparative and inductive). ${ }^{4}$

Calcium hydroxide, formocresol and glutaraldehyde are three common medicaments used in dentistry; however recent medicaments investigated include laser, electrosugery, freeze-dried bone, ferric sulfate, osteogenic proteins-1, bone morphogenic proteins, calcium-enriched mixture, nanohydroxyapatite and many herbal medicaments. ${ }^{5}$ In 1904, Bukley introduced formocresol for the treatment of putrescent pulp in animal teeth. The original formula prepared by Buckley consisted of concentrated cresol $35 \mathrm{gm}$, formalin $53 \mathrm{gm}$, glycerol $7 \mathrm{gm}$ and water $5 \mathrm{gm}$. Later the commercial formula of Bukleys solution consisted of $35 \%$ cresol, $19 \%$ formaldehyde, and glycerin in distilled water. ${ }^{6}$ Formocresol is a well known devitalizing agent and has been a popular medicament for pulpotomy procedures for many years. Despite its high success rates, its use as a pulpotomy agent has been questioned due to an intense pulpal inflammatory response, cytotoxicity, systemic disturbances, mutagenic and carcinogenic potential and immunologic response. ${ }^{4}$ All these disadvantages have led researchers to look for an alternative medicament for the pulpotomy procedures.

One of the optimistic alternatives to pulpotomy medicament is sodium hypochlorite, which is a bio-compatible material that is non-irritating and proved to be an effective hemostatic agent for the exposed pulp. Since 1920, it has been used as a common irrigant in endodontic treatments of permanent teeth which possessed a good antimicrobial property without being a significant irritant. ${ }^{7}$ Sodium hypochlorite has a remarkable effect in controlling bleeding of the pulp and thus can be expected to inhibit the formation of a fibrin clot. In a study conducted by Rosenfeld et al showed that when placement of 5\% sodium hypochlorite is done on noninstrumented vital pulp it acted only on the surface with minimal effects on the deeper pulpal tissues. ${ }^{8}$ Furthermore it helps in the removal of dentin chips along with disinfection of the pulpal canal. Thus, the study aimed at comparing the efficacies of formocresol and sodium hypochlorite when used as a medicament in pulpotomies of mandibular primary molars.

\section{MATERIAL AND METHODOLOGY}

Randomized 50, subjects aged between 3-6 years were selected from the general OPD of the Department of Pediatric And Preventive Dentistry, BRS Dental College and Hospital, Panchkula. Systemically health and cooperative subjects with at least one primary mandibular molar with extensive caries which required pulpotomy were selected. A brief discussion about the study and the time required for the follow up were informed to the parents of the subjects. After their agreement for the participation in the study, an informed consent was signed by the parents. Selection of the teeth became an important criterion for the study. A complete clinical and radiographic examination of the subjects tooth was done; exposed primary molars with vital carious pulp that bled on entering the pulp chamber and can be restored with a stainless steel crown were selected for the continuation of pulpotomy procedure. The tooth with no clinical evidence or any symptom of pulp degeneration, pain on percussion, mobility, nocturnal pain and/or spontaneous pain or sinus tract was excluded from the study. The tooth with internal/external resorption or furcation involvement was not included in the study.

Random allocation of the child was done to one of the groups using a coin toss system. The operating dentist couldn't be 
blinded due to the obvious differentiating smell of the two medicaments, hence the observer, assessing the outcomes of the treatment were blinded.

The randomly allocated children underwent pulpotomies using two different medicaments. After local anaesthetic administration, the selected tooth was isolated using a rubber dam. Followed by complete caries removal, coronal access was performed using a slow speed sterile bur. Coronal amputation was done using a sterile number 6 carbide round bur and a water moistened cotton pellet held with a tweezer to achieve hemostasis for no more than five minutes to ensure health of the pulp. After the control of bleeding, cotton pellet moistened with formocresol (1:5 Buckley's solution) for one minute in group I and 3\% sodium hypochlorite for 30 seconds in group II was placed on the pulp stump. After removal of the pellet moistened with pellet, the cavity was the rinsed with sterile saline and a dressing of zinc oxide eugenol (Denstply) was placed over the dressed pulp stumps before the placement of stainless of steel crown (3M ESPE). The crowns placed were luted using glass ionomer cement and the procedure was followed with all the 50 patients.

The children were recalled after 1,3 , 6 and 12 months for radiographic and clinical evaluation. Two blinded observers of the same profession were called for the clinical and radiographic examination of the patients.

Statistical analysis: the data obtained from the blinded observers, was collected and transferred into an excel sheet. SPSS software, version 20, was used for the evaluation of the results. Chi square test was used to evaluate the statistical differences between the treatment outcomes. Frequencies, percentage, mean, and standard deviation was used to represent the categorical variables. Bar diagrams was used to represent the data and a p-value of 0.05 was used as a significant value.

\section{RESULTS}

\begin{tabular}{|c|c|c|c|c|c|}
\hline \multicolumn{2}{|l|}{ Parameters } & \multirow{2}{*}{$\begin{array}{c}\begin{array}{c}\text { Frequencies } \\
(\mathbf{N})\end{array} \\
36 \\
\end{array}$} & \multirow{2}{*}{$\begin{array}{c}\begin{array}{c}\text { Percentages } \\
(\%)\end{array} \\
72 \\
\end{array}$} & \multirow{2}{*}{$\begin{array}{l}\text { Mean } \\
3.520\end{array}$} & \multirow{2}{*}{$\begin{array}{c}\begin{array}{c}\text { Standard } \\
\text { Deviation }\end{array} \\
0.931\end{array}$} \\
\hline \multirow[t]{4}{*}{ Age } & 3 Years & & & & \\
\hline & 4 Years & 5 & 10 & & \\
\hline & 5 Years & 6 & 12 & & \\
\hline & 6 Years & 3 & 6 & & \\
\hline \multirow[t]{2}{*}{ Gender } & Male & 42 & 84 & \multirow[t]{2}{*}{1.160} & \multirow[t]{2}{*}{0.370} \\
\hline & Female & 8 & 16 & & \\
\hline \multirow[t]{4}{*}{ Tooth For Treatment } & 74 & 12 & 24 & \multirow[t]{4}{*}{75.640} & \multirow[t]{4}{*}{3.947} \\
\hline & 75 & 28 & 56 & & \\
\hline & 84 & 6 & 12 & & \\
\hline & 85 & 4 & 8 & & \\
\hline
\end{tabular}

Table 2: Radiographic Evaluation at Different Time Intervals

\begin{tabular}{|c|c|c|c|c|c|}
\hline \multicolumn{2}{|l|}{ Groups } & 1 Month (N/\%) & 3 Month (N/\%) & 6 Month (N/\%) & 12 Months (N/\%) \\
\hline \multirow[t]{2}{*}{ Formocresol (Group I) } & Success & $21 / 84$ & $20 / 80$ & $18 / 72$ & $15 / 60$ \\
\hline & Failure & 4 & 5 & 7 & 10 \\
\hline P-Value & \multicolumn{5}{|c|}{0.63} \\
\hline \multirow[t]{2}{*}{3 \% Sodium Hypochlorite (Group II) } & Success & $23 / 92$ & $21 / 84$ & $20 / 80$ & $19 / 76$ \\
\hline & Failure & 2 & 4 & 5 & 6 \\
\hline P-Value & \multicolumn{5}{|c|}{0.05} \\
\hline
\end{tabular}

On evaluating the study patients after 12 months of the follow, all of the subjects $(100 \%)$ were available for reevaluation. Every patient was evaluated successfully using radiographs and by clinical examination by the blinded observer. After 1 month of evaluation, 4 patients from formocresol and 2 patients from 3\% sodium hypochlorite groups underwent failure with 3 of them having internal resorption and 3 had external resorption. On evaluation of patients after 3 months 5 teeth showed failure (1=radiographic radiolucency, 2=internal 
resorption, 2=external resorption) in formocresol and 4(2=radiographic radiolucency, $1=$ internal resorption, $1=$ external resorption) in $3 \%$ hypochlorite group. Similar results were observed after 6 and 12 months where 7 (3=radiographic radiolucency, $2=$ internal resorption, $2=$ external resorption) in group $\mathrm{I}$ and 5 ( $2=$ radiographic radiolucency, $1=$ internal resorption, $2=$ external resorption) in group II, while 10 (4=radiographic radiolucency, 4=internal resorption, $2=$ external resorption) in group I and 6 (2=radiographic radiolucency, $2=$ internal resorption, $1=$ external resorption, $1=$ periapical radiolucency) in group II respectively were considered as failures. Statistically significant differences were detected between the two groups at all the follow-up periods $(p=0.05)$. None of the subjects observed any adverse events or side effects during the study.

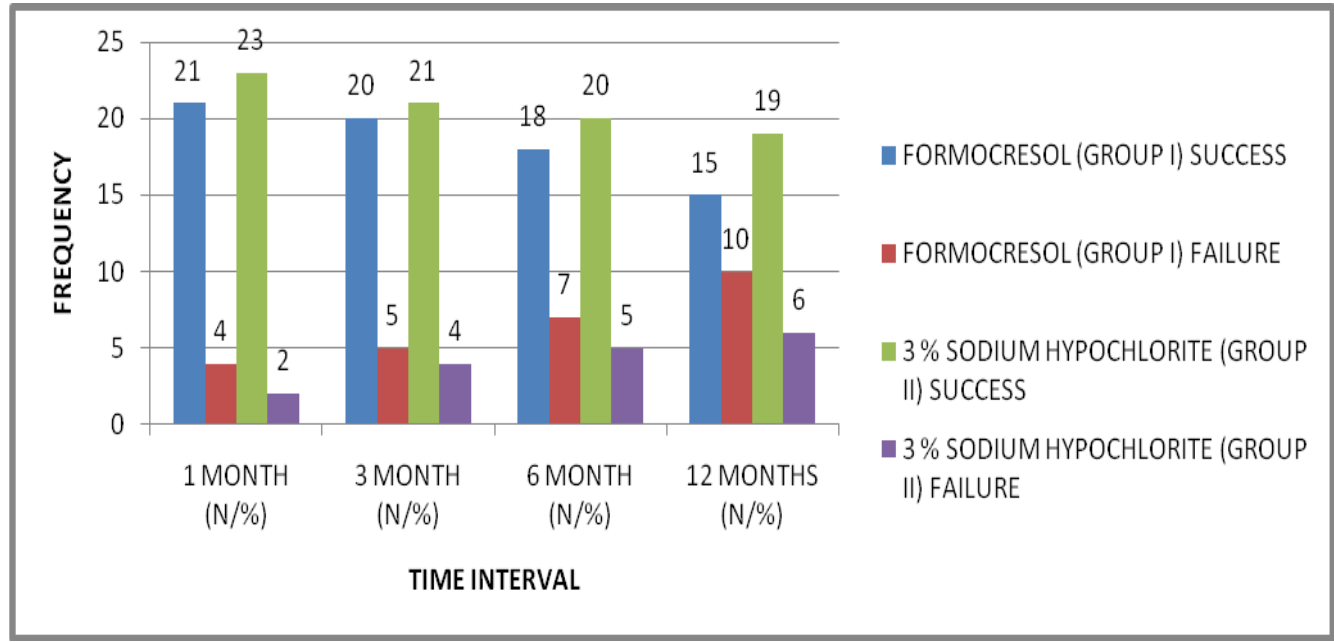

Table 3: Representing the Radiographic Appearance of the Pulp in the Assessed Pulpotomized Primary Teeth at 1, 3, 6 and 12 Months

\begin{tabular}{|c|c|c|c|c|c|c|c|c|c|c|c|c|c|c|c|c|}
\hline Groups & \multicolumn{4}{|c|}{1 Month } & \multicolumn{4}{|c|}{3 Month } & \multicolumn{4}{|c|}{6 Month } & \multicolumn{4}{|c|}{12 Month } \\
\hline & $\mathbf{R R}$ & IR & ER & PR & $\mathbf{R R}$ & IR & ER & PR & $\mathbf{R R}$ & IR & ER & PR & $\mathbf{R R}$ & IR & ER & PR \\
\hline Formocresol & - & 2 & 2 & - & 1 & 2 & 2 & - & 3 & 2 & 2 & - & 4 & 4 & 2 & - \\
\hline 3\% Soduim Hypochlorite & - & 1 & 1 & - & 2 & 1 & 1 & - & 2 & 1 & 2 & - & 2 & 2 & 1 & 1 \\
\hline
\end{tabular}

\section{DISCUSSION}

Several reasons are known to cause pulp exposure. Penetration of pulp due to caries is usually caused by the bacterial invasion which leads to pulpal inflammation. The main goal of vital pulp therapy is to treat reversible pulpitis and maintain pulp function and vitality where only inflamed coronal pulp tissue is removed and the unaffected radicular pulp tissue which is unable to heal when left to heal for itself. If the treatment proves to be successful, it usually precludes the need more extensive and expensive treatment of pulpectomy. Number of medicaments has been investigated for use as pulpotomy agents. In a study, conducted by Nadin et al reported that there no reliable evidence to prove the most appropriate technique or agent for pulpally involved primary molars. ${ }^{9}$ Therefore, our study aimed mainly at comparing the efficacy of two different medicaments radiographically and clinically.

On evaluating the results, no major statistically significant difference was obtained between the groups after 1, 3, 6 and 12 months. In group I, formocresol clinical success which decreased over the period of time of 1 month, 3 month, 6 month and 12 month from 84\%, 80\%, 72, and $60 \%$ respectively. While in case of $3 \%$ sodium hypochlorite, the clinical success rates were approximately $100 \%$ while radiographic success rates ranged from $92 \%, 84 \%, 80 \%$ and $76 \%$ respectively at 1 , 3,6 and 12 month recalls. Our study was inconsistent with a prospective study 
conducted by Vargas et al, where they compared 5\% sodium hypochlorite and ferric sulfate as a medicament in pulpotomy, with radiographic success rates of $91 \%$ and $79 \%$ and $100 \%$ clinical success rates respectively. ${ }^{10}$ In another study conducted by Vostatek et al in the year 2011, reported a lower success rate with clinical and radiographic success rates of 95 and $82 \%$ respectively. ${ }^{11}$

An acceptable dressing agent should be bactericidal, reasonably priced and biocompatible. A suitable medicament provides a bacteriometic seal, which when left open act as a medium for bacterial growth. Bacteria remaining in the pulp stump even after coronal amputation leads to an inflammatory response. On using an antibacterial agent is used, even in presence of existing micro-organism, a higher success rate is seen. Biological data reveals that dental pulp has an inherent capacity to heal even in the presence of bacterial infection. ${ }^{12}$

In dentistry, sodium hypochlorite has been in use since ages. Sodium hypochlorite does not impair the cellular healing of exposed dentin bridges and pulp formations and usually effects the vital pulp tissues superficially. Hafez et al in his study showed that primary pulp teeth when treated with $3 \%$ sodium hypochlorite showed no evidence of pulpal necrosis after 7 and 27 days. ${ }^{13}$ In 2006 Tunc et al also evaluated the use $3 \%$ hypochlorite to control hemorrhage in calcium hydroxide pulpotomies with no adverse effects. ${ }^{14}$ In our study, formocresol was used to compare the efficacy, as it is still considered as the standard therapeutic agent for treatment of pulpotomies in primary teeth. Mandibular molar were mainly selected due the reason of their early eruption and are the teeth mostly affected by early childhood caries.

Though, the standard time for formocresol use is just for 5 minutes, this time period has been determined as arbitrary leading to many side effects. Thus, many studies have concluded the use for one minute as the standard time for application. $^{15}$ Due to its potential side- effects, the use of formocresol was limited to one minute.

LIMITATIONS: sample size was the major limitation of the study. Due to Covid pandemic, the sample size couldn't be increased as a limited number of subjects visited the college premises. The design of the study was not a split mouth, as it was difficult to find children with at least two primary mandibular molars requiring pulpotomy. Due to the reason children with any one of the tooth were selected for the study.

\section{CONCLUSION}

Within the limitation it was concluded that, 3\% sodium hypochlorite proved to effective medicament to be placed on the root stump for the procedure of pulpotomy. Formocresol is considered as the gold standard and has been and still remains the most popular pulpotomy medicament for use and comparison with various new medicaments. The time period for its application and various clinical toxicities reported, has been limited its usage and various other medicaments like sodium hypochlorite have been recommended.

Acknowledgement: None

Conflict of Interest: None

Source of Funding: None

Ethical Approval: Approved

\section{REFERENCES}

1. Sonarkar S, Purba R. Bioactive materials in conservative dentistry. International Journal of Contemporary Dental and Medical Reviews 2015, Article ID: 340115, 2015. doi: 10.15713/ ins.ijcdmr.47.

2. Stanley HR. Conserving the dental pulp-can it be done? Is it worth it? Oral Surg Oral Med Oral Pathol 1989;68:628-39.

3. Kitasako Y, Inokoshi S, Fujitani M, Otsuki M, Tagami J. Short-term reaction of exposed monkey pulp beneath adhesive resins. Oper Dent 1998;23:308-17. 
4. Ranly DM. Pulpotomy therapy in primary teeth: new modalities for old rationales. Pediatric Dentistry. 1994 Nov 1;16:403-409.

5. Al-Dlaigan YH. Pulpotomy medicaments used in deciduous dentition: an update. The journal of contemporary dental practice. 2015 Jun 1;16(6):486-503.

6. Buckley JP. The chemistry of pulp decomposition, with a rational treatment for this condition and its sequelae. Amer Dent $\mathbf{J}$ 1904;3:764-771.

7. Orstavik D. Root canal disinfection: A review of concepts and recent developments. Aust Endod J 2003;29:70-4.

8. Rosenfeld EF, James GA, Burch BS. Vital pulp tissue response to sodium hypochlorite. J Endod 1978;5:140-6.

9. Nadin G, Goel BR, Yeung CA, Glenny AM. Pulp treatment for extensive decay in primary teeth. Cochrane Database Syst Rev 2003:CD003220.

10. Vargas KG, Packham B, Lowman D. Preliminary evaluation of sodium hypochlorite for pulpotomies in primary molars. Pediatr Dent 2006;28:511-7.

11. Vostatek SF, Kanellis MJ, Weber-Gasparoni K, Gregorsok RL. Sodium hypochlorite pulpotomies in primary teeth: A retrospective assessment. Pediatr Dent 2011;33: 327-32.

12. Cox CF, Tarim B, Kopel H, Gurel G, Hafez A. Technique sensitivity: Biological factors contributing to clinical success with various restorative materials. Adv Dent Res 2001;15:85-90.

13. Hafez AA, Cox CF, Tarim B, Otsuki M, Akimoto N. An in vivo evaluation of hemorrhage control using sodium hypochlorite and direct capping with a oneor two-component adhesive system in exposed nonhuman primate pulps. Quintessence Int 2002;33:261-72.

14. Tunc ES, Saroglu I, Sari S, Gunhan O. The effect of sodium hypochlorite application on the success of calcium hydroxide pulpotomy in primary teeth. Oral Surg Oral Med Oral Pathol Oral Radiol Endod 2006;102:e22e26.

15. Kurji ZA, Sigal MJ, Andrews P, Titley K. A retrospective study of a modified 1-minute formocresol pulpotomy technique part 2: effect on exfoliation times and successors. Pediatr Dent2011;33(2):139-43.

How to cite this article: Wani NI, Kour N, Verma $M$ et.al. Evaluation and comparison of formocresol and sodium hypochlorite as pulpotomy medicaments in treatment of mandibular primary molars - a randomized controlled study. International Journal of Science \& Healthcare Research. 2021; 6(4): 105-110. DOI: https://doi.org/10.52403/ijshr. 20211017 